\title{
Integrating Socio-Critical and Problem Oriented Approach to Assess Learner Performance in Acids and Bases in Secondary School Chemistry
}

\author{
Thelma Kaanza $^{1^{*}} \quad$ Kenneth Kakoma Maseka ${ }^{1,2}$ \\ 1.Luanshya Girls Secondary School, PO box 90085, Luanshya, Zambia \\ 2.School of Mathematics and Science, The Copperbelt University, PO box 21692, Kitwe, Zambia
}

\begin{abstract}
The main purpose of this study was to explore the effect of integrating socio-critical and problem oriented approach on performance of grade 11 learners in acids and bases. It also investigated the learner's attitudes towards chemistry and the benefits and challenges faced by teachers in contextualizing the teaching and learning of chemistry. The design of this study was mixed method design involving quantitative and qualitative research methods together (Creswell, 2008; Gray, 2009). The study was conducted in Luanshya district of the Copperbelt Province in Zambia at three selected senior secondary schools (using rotary). These schools are Luanshya Central Secondary School. Luanshya Girls Secondary School and Mpelembe Secondary school. The sample consisted of all 16 chemistry teachers from the selected schools and 98 learners from two intact grade 11 classes randomly selected from two core schools of the three schools involved. These are Luanshya Central Secondary School and Mpelembe Secondary School. A non-randomised quasi-experimental pre-test, post-test experimental and control group counterbalanced was used. Chemistry achievement test and a five likert scale chemistry attitude questionnaire was used for quantitative data collection. Qualitative data was collected using audio recorded structured interviews. The experimental group was taught using integrating socio-critical and problem oriented approach while the control group was taught using conventional methods (discussion) method. An independent ttest at alpha 0.5 was conducted to analyse the results of pre-test and post-test. The significant difference in posttest was $\mathrm{p}=0.003$ with mean score difference of 39.7 at $t$-value of 8.542 . Results from the chemistry attitude test revealed that learners had positive attitudes towards chemistry having learner using socio-critical and problem oriented approach. Also qualitative data from interviews was analysed using content analysis technique on excel windows 7 . The results showed that teacher's challenges ranged from topic difficulty to lack of apparatus to use in lessons. Therefore, integrating socio-critical and problem oriented approach in the teaching of acids and bases at secondary school had a positive effect on learner performance. Both groups showed a significant difference with socio-critical and problem oriented approach than with conventional method.
\end{abstract}

Keywords: socio-critical and problem oriented approach, performance, attitudes, conventional method

DOI: $10.7176 / \mathrm{EJBM} / 11-23-08$

Publication date: August $31^{\text {st }} 2019$

\subsection{Introduction}

Science education is very important in sustainable development. This is true not only for Africa but for the whole world. Science is in all places. The study by Lazarowitz, (1994) showed the science is so unpopular in most countries more so Africa. One of the reason is considered to be that scientific knowledge is taught with an approach that is too content driven and which puts an emphasises on the systematic treatment of science too strongly ( Johnstone \& Reid, 1981; Lijnse, 1995 ;Donnelly, 1999; Osborne, 2001). Therefore, science lessons and science in itself seem to be so irrelevant for the students, this is because learners cannot understand their importance their everyday living and for the future encounters.

Chemistry education is very important in education that embraces sustainability in its developmental issues (Bradley, 2005). This is so because many products in our daily lives are based on chemistry, the chemical industry has a major potential for focusing on the environment in terms of both the production process and the end product. Learners must be able to discuss effects of chemistry on the future and also bring on board ideas for sustainable communities so as to be good stewards of the available natural resources (Burmeister \& Eilks, 2012). Chemistry is embedded in many areas of business, government, and environmental management that some background in the subject can be useful in fields as varied as product development, marketing, management, computer science, technical writing, and even law (Lower, 2018). Tenaw Y.A (2014) in his study affirmed to the fact that Chemistry is at the center of all sciences due to its peculiar language. And that good strategies need to be found using important and applicable means that can make chemistry easy and funny to learn.

Chemistry is also important in sustainability issues outside the professional world. Chemical knowledge is necessary for everyone to understand many issues that threaten the sustainability of our planet, such as the potential side effects on our personal lives caused by the production of goods. (Schmidt \& Wolfe, 2009).

The use of contextual teaching and learning (CTL) in chemistry by environmental issues suggests an effective 
method of motivating the students to learn chemistry (Mandler, Blonder, Yayon, Hofstein and Mamlok-Naaman, 2014). Adding sustainability and environmental contexts can contribute to the students' perceptions of how relevant chemistry is to real-life problems and this will raise motivation (Eilks,2002). Motivating the students to study science, through the provision of a good understanding of chemical concepts, was ranked among the most important concerns in chemistry education (Zoller and Pushkin, 2007)

Contextual teaching and learning uses context-based approaches such as socio critical and problem oriented approach (SCPOA) to extend to the real world using applications to introduce a scientific concept meaningfully. More traditional approaches introduce concepts from unknown to the known. Contextual Teaching and Learning (CTL) helps to answer the 'why? ' in the minds of a student. An understanding of why this is vital in chemistry learning, 'why I should learn this information' helps them to look at a topic in a more positive state of mind. Sociocritical and problem oriented approach (SCPOA) was first used in Germany (Eilks, 2000). It was used to teach the chemistry on biodiesel. Socio-critical and problem-oriented approach involves providing students with sociocritical issues taken from the students' everyday life or from their communities that trigger a discussion and as well help in the learning of science content knowledge (Eilks et al, 2008). This approach helps to motivate teachers and students in science class, as well as contribute to develop communication and evaluation skills, which are vital in educating a responsible citizen for not only now but the future too.

In chemistry education, SCPOA is relevant both with respect to understanding scientific working methods and to gaining a more holistic understanding of chemistry related issues. A person equipped with chemical literacy needs to use his or her chemical understanding as a consumer, in decision-making; in the social debate regarding chemistry-related issues and how discoveries in chemistry may impact processes of a sociological nature (Shwartz et al., 2006). In chemistry education, this may be attained through investigating environmental, social and economic factors in addition to the chemical content of a specific case.

Therefore, the understanding of the relations and interdependence of nature, society and the economy is considered central to achieving sustainability (UNESCO, 2012). Thus, the subject of chemistry must be taught in a contextualized form consistently relating content knowledge to everyday phenomena, better student ability to transfer knowledge is expected. SCPOA suggest that integrating science learning into contexts will help the students to appreciate the meaningfulness of the learnt science and also build the knowledge they can apply in various socio problem-solving situations (Eilks et al., 2013).

However, in a study conducted by Osborne and Collins (2001) it was found that learner were much able to relate biology content to their experiences than they would physics and chemistry contents. Therefore, this poses the need for a study to be done on how chemistry content can be related to everyday context. Teaching needs to present chemistry ideas in ways that are authentic representations of the scientific concepts, yet in a manner that would be meaningfully understood by the learners. To start with, areas of difficulty in the local contexts of teaching learning must be pinpointed. If areas of difficulty are identified, then teacher ought to employ innovative strategies in a more economic and focused way to remedy student difficulties in those areas and chemistry as a whole. This study has been a step in this direction.

\subsection{Methodology}

\subsection{Research Design}

The design of this study is a mixed methods design. Mixed methods design involves using quantitative and qualitative research methods together in the same study (Creswell, 2008; Gray, 2009). A non-randomized quasiexperimental pre-test, post-test and post-test experimental and control group counterbalanced will be used in this research.

\begin{tabular}{|c|c|c|c|c|}
\hline $\begin{array}{ll}\text { GROUP } & \text { PRE-TEST }\end{array}$ & TREATME & TES & ГМ & \\
\hline EXPERIMENTAL $\mathrm{O}_{1}$ & $\mathrm{X}$ & $\mathrm{O}_{2}$ & & \\
\hline CONTROL & - & $\mathrm{O}_{2}$ & $X$ & $C$ \\
\hline
\end{tabular}

Where:

$\mathbf{O 1}$ is the observations that will be made in pre-test measures. Both the experimental and control groups will be given a Chemistry achievement test as pre-test measure.

$\mathbf{X}$ is the treatment that will be employed in order to assess its effects on pupils' performance in Chemistry. The experimental group will be taught on acids and bases through the integration of relevant knowledge through sociocritical and problem oriented approach in chemistry lessons. The control group will be taught using conventional method approach

$\mathbf{O 2}$ is the observations to be made in post-test. Both the experimental and control groups will be given the Chemistry achievement test as post-test measure. Then comparisons will be made between pretest and post-test performance of both groups.

$\mathbf{O 3}$ is the observation to be made in counterbalanced post -test. Both the experimental and control will be given chemistry achievement test. The result can be used to verify the finding from observation $\mathrm{O} 1$ and $\mathrm{O} 2$. 


\subsection{Research Site}

The study was conducted in Luanshya district of the Copperbelt Province at three selected senior secondary schools (using rotary). And these schools are Luanshya Central Secondary School, Luanshya Girls High School and Mpelembe Secondary School.

\subsection{Study population and participant}

The population of this study comprised of all chemistry teachers in the selected Government Senior Secondary schools in Luanshya district. The selected senior secondary schools of Luanshya district have a population of 2400 pupils that includes grade $8,9,10,11$ and 12 , with a 26 science teachers. These teachers some major in chemistry with different minor subjects while others have majored in other subjects and minor in chemistry, some are science teachers who teach two subjects such as Chemistry and Biology, Chemistry and Physics, and Physics and Biology. The participants at the three selected secondary schools were the chemistry teachers and grade 11 pupils.

\subsection{Sample and Sampling Procedure}

The sample consisted of all 16 chemistry teachers from the three selected schools and about 98 learners (constituting 2 classes of about 48-50 learners each), a total sample of 114 participants. The researcher purposively selected two schools from the selected three schools and two groups (classes) from the two that were selected among the three secondary schools in Luanshya district, the grade 11 classes were purposively selected, due to the topic used in the study, acids and bases, which is taught at grade 11. The two groups (classes) were randomly selected, one group (class) assigned as experimental and the other one as control group (Tichapondwa, 2011). The study did not involve the randomising of subjects into experimental and control groups but were left as intact classes. This was to avoid the disruption of the school programs, the classes have different option subjects.

\subsection{Data collection instruments}

The instruments used in the study were the questionnaire for attitudes towards chemistry, semi-structured interviews and a chemistry achievement test (CAT)

Data on learners' attitudes towards chemistry was collected using a modified questionnaire for attitudes towards chemistry developed by the faculty of education, Cambridge University. It will have two parts. Part 1 will have four items on demographics.

The second section includes 5 point Likert-scale statements chemistry learning. Learners were asked to select Strongly Agree, Agree, Neutral, Disagree, or Strongly Disagree with regard to the statements concerning chemistry learning.

\section{Semi-structured interviews}

A semi-structured interview of five (5) open-ended questions will be conducted on chemistry teachers. This will be aimed at finding out the challenges faced in contextualizing chemistry.

\section{Achievement test}

A self-constructed chemistry achievement test was used in the study. The instrument had three parts; the first part seeks response on students' personal data such as name, school and class while part 2 is based on question items on the concepts of acids and bases. It consisted of 8 multiple choice items with four (4) options which are scored 2 marks each and part 3 involved three short answer questions scored 1 mark each blank. The instrument had a total of $100 \%$. Students who scored below $50 \%$ were considered to have scored below pass mark, while those that scored $50 \%$ and above were scored above pass mark.

\subsubsection{Instrument validity and reliability}

\subsubsection{Validity of the Instruments}

The questionnaire used had been validated and proved for effective response. While the semi-structured interview and achievement test used in the study were self-developed by the researcher. After drafting the eleven (11) test items for the achievement test, experts were used to validity the instrument with the objectives and hypotheses of the study. The final copies were then compiled after necessary corrections had been done.

\section{Pilot study}

A pilot study was conducted to establish the suitability of the instrument (achievement test). Forty (40) pupils from Luanshya Girls Secondary School of Luanshya District of the Copperbelt Province of Zambia, selected purposively for the pilot study. The purpose of the pilot study was to determine the reliability co-efficient of the instrument of the study through a trial run (Creswell, 2008).

\subsubsection{Reliability of the Instrument}

Reliability of the selected Likert-scale sections of the questionnaire was determined by computing Cronbach's alpha values. (Cohen, 1988).

For the achievement test, Test-retest reliability was used to measure reliability by administering the same test twice over a period of time to the same group of individuals. The two scores were then correlated in order to evaluate 
the test for stability over time.

\subsection{Results of the study}

\subsection{Pre-test Results}

Experimental and control groups results for pre-test.

In order to find whether any significant differences existed between the pre-test mean score of the control and experimental groups with regards to being taught using the socio-critical and problem oriented approach to assessing leaners in acids and bases, an independent sample t-test was performed as illustrated in Table as follows.

Table 1; Results of the independent t-test on the pre-test of both groups

\begin{tabular}{lllll}
\hline Variable & Mean & Std. Deviation & T-value & Sig(2 tailed) \\
\hline Experimental (45) & 27.69 & 11.801 & 18.478 & .000 \\
Control (53) & 16.47 & 3.277 & 5.180 & 0.1014 \\
\hline
\end{tabular}

T-value significant at $\mathrm{p}<0.05$

Table 5.3 shows that the control group obtained a mean score of 16.47 while experimental group obtained a mean score of 27.69. The mean score difference between the groups was 11.22 with $t$-value of 13.298 . Nonetheless, the $p$-value was $0.1024(p<0.05)$ indicating that the difference in the mean score was not significant. This result illustrated that both the students in the control and experimental group were similar in abilities before the treatment was administered.

\subsection{Post-test results}

Table 2; Results of independent t-test on the post-test of both groups

\begin{tabular}{lllll}
\hline Variable & Mean & Std. Deviation & T-value & Sig(2 tailed) \\
\hline Experimental (45) & 44.84 & 24.506 & 14.524 & .000 \\
Control (53) & 5.14 & 1.015 & 5.982 & .003 \\
\hline
\end{tabular}

To determine whether any significant differences exist between the post-test mean score of the control and experimental group, an independent sample t-test was carried out. Table 5.4.2 shows that the control group obtained a mean score 5.14, while the experimental group obtained a value of 44.84 . The mean score difference between the groups was 39.7 with a $t$-value of 8.542 . However, the p-value was low at $0.003(p<0.05)$, indicating that the difference in the mean score of the groups was significant.

\subsection{Students Response Rate}

This section presents the various responses obtained from the student's questionnaires. The results are presented using the mean and standard deviation.

Table 3; Attitudes toward chemistry

\begin{tabular}{|l|l|l|}
\hline & Mean & Std. Deviation \\
\hline The chemistry we learn at school is useful in other subjects & 4.59 & .592 \\
\hline Understanding the chemistry we are doing is important & 4.85 & .536 \\
Chemistry is boring & 1.67 & 1.150 \\
I usually manage the chemistry we do at school & 4.33 & 1.001 \\
I would like a job that involves using chemistry & 4.15 & 1.228 \\
I like learning chemistry & 4.85 & .382 \\
I look forward to doing chemistry & 4.04 & 1.289 \\
School chemistry is useful to life in today's world & 4.66 & .901 \\
I find chemistry difficult & 2.30 & 1.395 \\
I will avoid chemistry once i leave school & 2.25 & 1.632 \\
Even when it gets hard, i can do our chemistry work & 4.47 & .885 \\
I want to make sense of what i learn in chemistry & 4.71 & .870 \\
Learning chemistry is important for getting a job in future & 4.32 & 1.243 \\
I find chemistry interesting & 4.54 & .942 \\
I like to know the thinking behind chemistry i am studying & 4.44 & 1.068 \\
\hline
\end{tabular}

\subsection{Results from the Interviews}

The responses from the five structured interview question were analysed using content analysis technique. Below are some of the opinions of the chemistry teachers interviewed:

1. What is your opinion on the use of Real Life examples in teaching and Learning Chemistry? The responses are summarized in the table as follows. 


\section{Table 4; Real life teaching of chemistry}

\begin{tabular}{|l|l|l|}
\hline Item & Frequency & Percent (\%) \\
\hline Learners are able to relate what they learn in class to real life & 5 & 31 \\
Enhancing level of understanding & 9 & 56 \\
Involving of the learners & 2 & 13 \\
Total & 16 & 100 \\
\hline
\end{tabular}

According to the results obtained $5(31 \%)$ of the respondents indicated that learners are able to relate what they learn in class to real life context while $9(56 \%)$ were of the view that the technique enhances their understanding of the subject. Only $2(13 \%)$ revealed that the technique involves the learners.

\section{How would you describe a contextualize Chemistry Lesson}

The researcher also sought to determine how the various interviewees could describe a contextualize chemistry lesson. The results obtained are depicted in Figure 5.2 below:

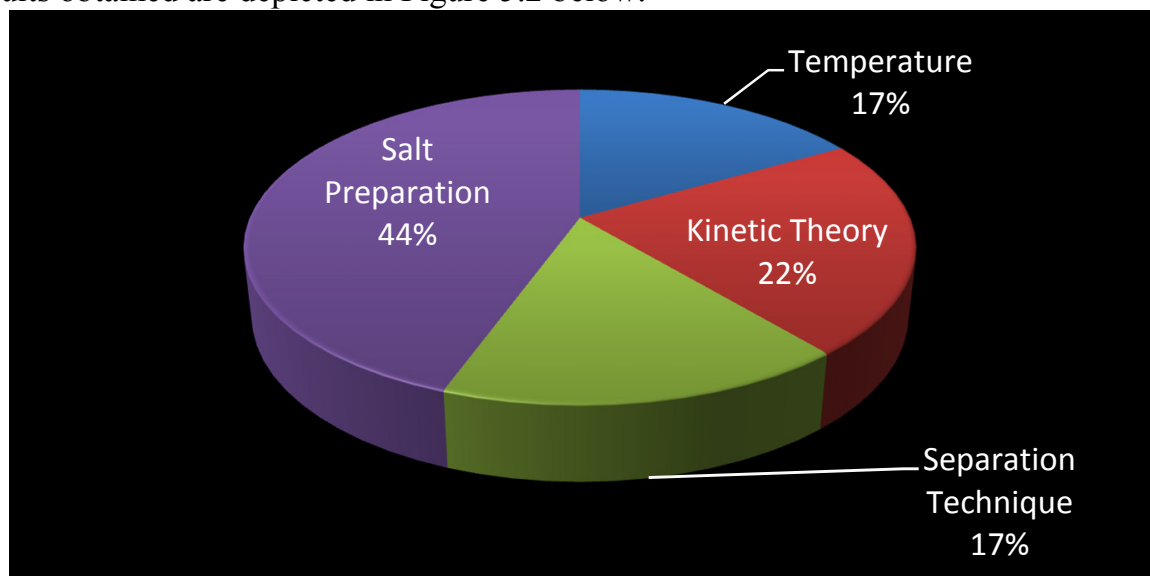

Figure 1; contextualization Description

\section{What are the challenges you face in contextualizing chemistry lessons?}

Furthermore, the researcher wanted to know the challenges that teachers of chemistry tend to face in their effort to conceptualize chemistry lessons. The results obtained are represented in the table below:

Table 5: Challenges of Contextualization

\begin{tabular}{|l|l|l|}
\hline Item & Frequency & Percent (\%) \\
\hline Some topics are difficult to conceptualize & 2 & 13 \\
Lack of Equipment & 6 & 37 \\
Lack of Laboratories & 8 & 50 \\
Total & 16 & 100 \\
\hline
\end{tabular}

According to the respondents, certain topics are not easy to find a perfect example in nature (13\%). One such topic is explaining an atom, ionic bonding among others. Respondents were of the view that, it is not easy to relate atoms and ionic bonding in nature and this make it difficult to contextualise this topic. It was revealed that certain concepts are not easy to relate to nature in a lesson and this makes it a big challenge to contextualise the lesson. The respondents stated that much of the lessons are inclined to teaching pupils for them to just pass the exams, hence the difficult in conceptualizing the course.

Respondents also revealed that lack of Equipment (37\%) to use in certain experiments and none-availability of chemicals in their science laboratories is another challenge that they face in their attempt to contextualise chemistry lessons. Without proper apparatus, it is difficult to conceptualize in practical form chemistry lessons.

Other respondents stated the lack of lab as a major challenge to contextualization $(50 \%)$. They were of the view that, once school laboratories are fully equipped with all the needed apparatus and, in cases where there are no apparatus field trips are provided, contextualizing chemistry lessons may be made easy.

4. What are some Positive and Negatives impacts experienced in teaching Chemistry?

In addition, the researcher sought to know the positive and negative impacts experienced in teaching chemistry. According to the results obtained the following where the positive experiences in teaching chemistry:

$>$ That chemistry caters across all science area and forms the broad base for the science, this helps chemistry teachers to understand it better

$>$ That chemistry is applicable to all aspects of life

$>$ That they are able to apply chemistry at home, prepare chemicals and come up with good exams.

$>$ That since science is dynamic, they keeps learning new things

$>$ That through chemistry, they have acquired knowledge on how chemicals are prepared i.e. preparation of soap 
$>$ That they have gained knowledge of handling chemicals as well as preparing iodine solutions in the labs since the subject has opened up on their mind.

$>$ They are able to acquire knowledge in soap production

Beside the positive impacts of teaching chemistry, there also negatives that were outlined by the respondents. Among the prominent ones include:

$>$ There is growth in drug abuse since someone with chemistry knowledge can manufacture illegal drugs.

$>$ That learners tends to misappropriate chemistry concepts

$>$ That Health can be affected, in terms of dealing with chemicals for a prolonged period.

$>$ That lack of apparatus, materials, and laboratories in schools makes it difficult to teach chemistry.

$>$ That large number of students makes it hard to conduct the experiments and because of this, chemistry is taught theoretically.

$>$ That lack of protective clothing for use in the laboratories impact negatively in teaching chemistry since leaners are not exposed to practical in the way chemistry lesson is taught.

5. What changes do you perceive in the attitude of the leaners when Chemistry is conceptualized? Finally, the researcher sought to determine the changes that teachers perceive in the attitude of the leaners when Chemistry is conceptualized. The figure below illustrates the attitudes:

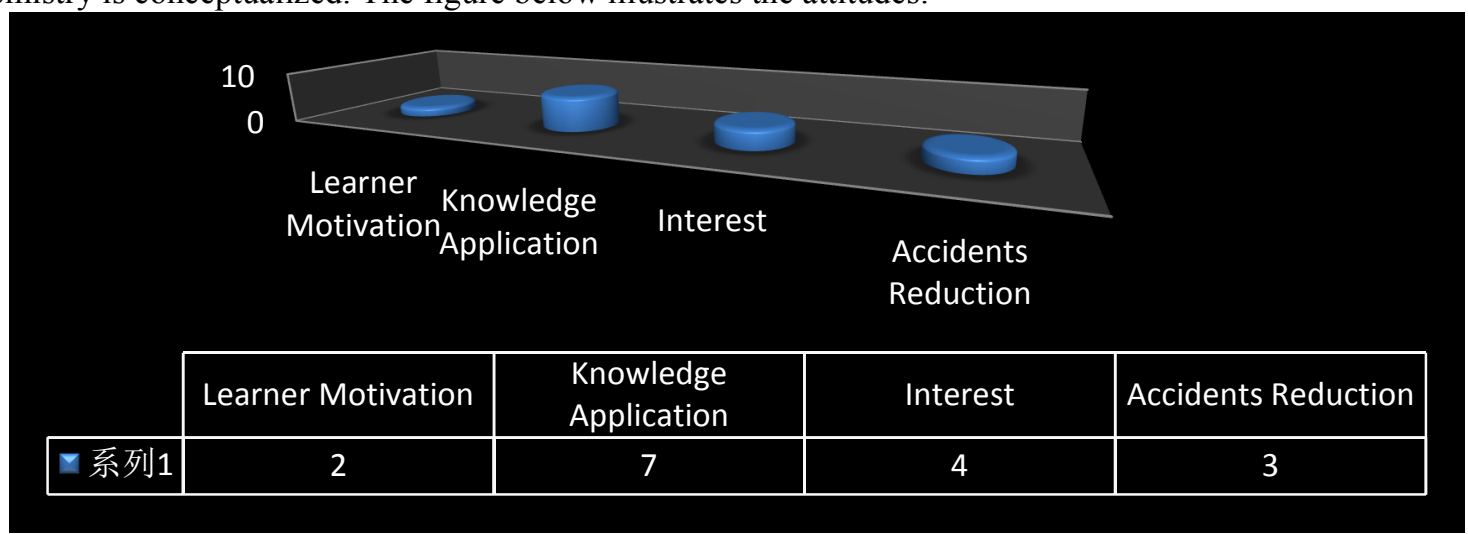

Figure 2; Attitude of learners

According to the responses obtained, it was revealed that intrinsic motivation ( 2 respondents) in the learners increases when chemistry is contextualised. This in tells that the leaners are able to practice chemistry outside the classroom environment thereby building confidence in the course.

It was also established that application ( 7 respondents) of chemistry by pupils and reduction in the accidents that are connected to chemistry is another positive attitude when chemistry is contextualise. Learners are now more careful in dealing with chemicals that that could potentially be dangerous if not properly handled. This has therefore, enhanced the understanding of the importance of chemistry as a science, since the leaners are able to apply it to their real life while exercising caution.

In addition, the respondents were of the view that contextualizing chemistry lessons enable learners develop interest (6 respondents) in the subject and have a great impact on the environment. This is because the technique increases the level of understanding of the pupils. The technique also motivates learners because they have to learn concepts similar to what they come across in the real time environment. In this case, leaners are able to acquire psycho motor skills and interest in learning chemistry because their understanding of concepts is better than ever.

\subsection{Discussion of findings}

5.1 Effect of integrating socio-critical and problem oriented approach on learner performance in acids and bases

The results of this study revealed that integrating socio-critical and problem oriented approach in teaching and learning of chemistry has a positive effect on the performance of learners at secondary school. The results also suggested that when socio-critical and problem oriented approach is integrated in teaching and learning of chemistry learners attitudes towards chemistry are enhanced.

\subsection{Conclusions}

The results of this study have established that the use of socio-critical and problem oriented approach affects learner performance positively. This was proved by the results indicated show mean score of control group, 5.14 against mean score of experimental group at 44.84, giving p-value for control as low as 0.003 while the set alpha is at $0.05(\mathrm{p}<0.05)$. This showed that there was a significant difference. The experimental performance much better than the control group

The study has also revealed several teachers have challenges in contextualizing chemistry lessons due varies 
reasons. The reasons range from certain topic difficulty to contextualize, as in the case of abstract nature of Atoms, to lack of equipment for use in schools. The results attest the fact that the use of socio-critical and problem oriented approach improves learners' attitudes towards chemistry. They relate well with the subject contents since the approach helps them to find relevance of the chemistry learnt to the real-life issues.

Additionally, the study has confirmed that contextualizing chemistry increase critical thinking and analytical decision making in their daily life.

\subsection{Recommendations of the study}

Based on the findings from the study, the following recommendations were made:

1. That the socio-critical and problem oriented approach to assessing learner performance in acids and bases should be integrated in school curriculum to enhance the skills of learners in the subject.

2. Deliberate policies that compel the chemistry teachers to aim at contextualizing their lessons in order to help learners relate the knowledge obtain to their everyday life.

3. That policy makers and schools should aim at ensuring that chemistry laboratories are well equipped.

\subsection{Recommendations for future research}

1. This study only integrated socio-critical and problem oriented approach in the teaching and learning of acids and bases. Further research should be done find out the effect the approach has on learner performance in other chemistry stated difficulty topics.

2. Research should be undertaken in other science subjects too.

\section{ACKOWLEDGEMENT}

Author would like to appreciate the support rendered by The Copperbelt University, school of mathematics and natural sciences in order for this study to reach completion. The authors would like to also thank the selected schools of Luanshya district for allowing the study to be carried out.

\section{REFERENCES}

Burmeister, M \& Eilks, I. (2012). Education for sustainable development (ESD) and chemistry education. Chemistry education research and practice 13 (2), 59-68.

Bradley, J. D. (2005). Chemistry education for development. Chemical Education International,6(1), 1-6.

Creswell, J. (2008). Research Design: Qualitative, Quantitative and mixed methods Approaches. London: SAGE.

Donnelly, J. (1999). interpreting differences: The educational aims of teachers of science And history and their implications. Journal of Curriculum Studies, 20, 585-596.

Eilks, I., Marks, R., \& Feierabend, T. (2008). Science education research to prepare future Citizens: Chemistry learning in a socio-critical and problem-oriented approach. The worth of science education research (pp. 7586). Aachen, Germany: Shaker.

Eilks, I. (2000). Promoting scientific and technological literacy: teaching biodiesel. Science Education International, 11(1), 16-2

Eilks et al (2013). The meaning of relevance in science and its implications for science curriculum. Researchgate Gray, D.E. (2009). Doing research in the real world $\left(2^{\text {nd }}\right.$ Ed). Thousand Oaks, California: SAGE Publications Inc.

Johnstone, A. H. \& Reid, N. (1981).Toward a model for attitude change. European Journal of Science Education, 3, 205-221.

Lazarowitz, R., Hertz, R. L., Baird J. H., \&Bowlden, V. (1988). Academic achievement and on-task behaviour of high school biology students instructed in a cooperative small investigative group.. Science Education, 72,475-487.

Lijnse, P. L. (1995). "Developmental research" as a way to an empirically based "didactical Structure" of science. Science Education, 79, 189-199.

Lower, S. (2018). What is chemistry all about? http://www,chem 1.com.

Mandler, D., Blonder, R., Yayon, M., Hofstein, A., \&Mamlok-Naaman, R. (2014). Exploring the environment through analytical chemistry-oriented curricula for high school students. Journal of Chemical Education, 91(4), 492-496.

Osborne, J. F. (2001). Science education for contemporary society: Problems, issues and Dilemmas. In: O. de Jong, E. R. Savelsbergh \& A. Alblas (eds.), Teaching for scientific literacy. Utrecht: cdB.

Osborne, J., \& Collins, S. (2001). Pupils' views of the role and value of the science curriculum: A focus-group study. International Journal of Science Education, 23(5), 441-467.

Osborne, J.F. (2007). Science education for the twenty first century. Eurasia Journal of Mathematics, Science \& Technology Education, 3(3), 173-184.

Shwartz, Y., Ben-Zvi, R., \&Hofstein, A. (2006).The use of scientific literacy taxonomy for Assessing the development of chemical literacy among high-school students. Chemistry Education Research and Practice, 
7(4), 203-225.

Tenaw, Y.A (2014). Effective strategies for teaching chemistry; international journal of Education research and review ISSN, 2329-9843. Vol 3, pp 078-084

Tichapondwa, S. (2013).Preparing your dissertation at a distance: A Research Guide. Vancouver: Virtual University for small states of the collon wealth.

UNESCO, (2012). Shaping the education of tomorrow: 2012 full-length report on the UN Decade of Education for Sustainable Development. Paris: Author.

Zoller, U. \& Pushkin, D. (2007). Matching Higher-Order Cognitive Skills (HOCS) promotion goals with problem-based laboratory practice in a freshman organic chemistry course. Chemistry education Research and Practice, 8,153-171. 